\title{
Endogenous NGF and Nerve Impulses Regulate the Collateral Sprouting of Sensory Axons in the Skin of the Adult Rat
}

\author{
Jack Diamond, Michael Holmes, and Michael Coughlin \\ Department of Biomedical Sciences, McMaster University, Hamilton, Ontario, Canada L8N $3 Z 5$
}

We have investigated the co-involvement of endogenous NGF and impulses in the collateral sprouting of cutaneous sensory nerves in adult rats, specifically the A $\delta$-axons involved in mechanonociception and the C-fibers that mediate heat nociception. Their collateral sprouting was measured by the progressive expansion, respectively, of the behaviorally defined "pinch" and "heat" fields into surrounding denervated skin (the light-touch A $\alpha$-fibers do not sprout in adult mammals). The expansions of such "isolated" fields were totally prevented in animals injected daily with antiNGF serum, but developed normally after treatment was discontinued. Light microscopic and EM examination of the skin confirmed that the effect of the anti-NGF treatment was attributable to its prevention of collateral sprouting. Initiation of treatment would also rapidly halt sprouting already in progress. Finally, intradermal injections of purified NGF protein would not only increase the rate of nociceptive fiber sprouting, but also evoke sprouting de novo within normally innervated skin (again, A $\alpha$-axons were unaffected). We conclude that the collateral sprouting of intact nociceptive nerves following partial denervation of skin is entirely dependent on endogenous NGF. The observed latency of this sprouting was 10-12 d; we estimate, however, that at least $2 \mathrm{~d}$ of field expansion is required for its reliable detection. Thus, about 8-10 d are required for NGF levels in the skin to rise to effective levels, and for the neurons to respond and initiate sprouting. From indirect findings, the NGF component of this sprouting latency appears to be about $2 \mathrm{~d}$. In accord with earlier findings, the remaining "initiation time" was reduced by 5-6 $d$ if the neurons were briefly excited, even $2 \mathrm{~d}$ prior to the isolation of their fields. Unexpectedly, this phenomenon of "precocious sprouting" requires that endogenous NGF be available; the sprouting latency reverted to normal values when the conditioning impulses were evoked during a 2 d anti-NGF "umbrella." In contrast to the impulse-sensitive neuronal mechanisms involved in the initiation of sprouting, those underlying the sprouting rate were unaf-

Received July 26, 1991; revised Nov. 11, 1991; accepted Nov. 18, 1991.

This work was supported by the MRC (Canada) and by the MS Society of Canada. Partial support also came through the Canadian Centre of Excellence for Neural Regeneration and Functional Recovery. We are grateful to Bert Visheau for his preparation of material for EM and to Lynn Macintyre and Christine Bourgeau for their participation in some of the experiments. Jolanta Stanisz was largely responsible for the preparation of the NGF and antiserum to NGF. We also thank Anne Foerster, Andrew Gloster, Jim Fawcett, Yvonne Kril, and Karen Mearow for their comments on the manuscript.

Correspondence should be addressed to Dr. Jack Diamond, Professor and Head, Division of Neuroscience, Department of Biomedical Sciences, McMaster University, 1200 Main Street West, Hamilton, Ontario, Canada L8N 3Z5.

Copyright (C) 1992 Society for Neuroscience $0270-6474 / 92 / 121454-13 \$ 05.00 / 0$ fected by nerve activity and were entirely dependent on the level of endogenous NGF. We suggest that interactions like that revealed in these studies between a sprouting agent and impulses that seem to prime the neuron's response to it contribute to plasticity within the nervous system.

During early development, the growth, differentiation, and ultimately the survival of neurons are now assumed to be critically dependent on growth factors. For defined neuronal populations in the autonomic and sensory nervous systems, this factor has been shown to be NGF (Levi-Montalcini and Angeletti, 1968; Gorin and Johnson, 1979; Aloe et al., 1981; Goedert et al., 1984). Experimentally there are often difficulties in examining separately the NGF dependency of neuronal survival, axonal outgrowth toward the target tissue, and the axonal arborization that occurs within the target tissue itself. The earliest period during development that is amenable to testing by the preferred approach, the exposure of the fetus to antibodies to NGF, is approximately the time when sensory axons are arriving at their target tissues. The consequence of such an exposure is the disappearance of an entire population of sensory neurons, which includes those giving rise to the unmyelinated fibers and some of the small myelinated fibers (Johnson et al., 1980; Ross et al., 1981). Thus, NGF is certainly critical for neuronal survival at that stage of development. However, from developmental studies of the expression of NGF receptor on trigeminal axons, and of NGF in their target tissues (Davies et al., 1987), the initial outgrowth of these axons seems unlikely to be NGF dependent.

In the mature organism, NGF continues to be made in a variety of peripheral tissues and also within the CNS (Heumann et al., 1984; Shelton and Reichardt, 1984, 1986a; Whittemore et al., 1986). Nevertheless, the role of NGF in the adult is not at all clearly defined. There is evidence that NGF might be involved in the regulation of substance $P$ levels in certain sensory neurons (Schwartz et al., 1982), and of cholinergic markers in basal forebrain neurons (Gage et al., 1988; Hagg et al., 1988). However, in the fully differentiated adult nervous system, neurons can continue to express growth behaviors comparable to those seen during development. In some respects these neurons are more accessible for experimental study than the analogous ones in the fetus. For example, when nerve-depleted target tissue is available to undamaged fibers, they will often begin to sprout profusely within it, a growth resembling the initial ramification of axons within their target tissuc during development (Diamond et al., 1976). Also, after they are damaged, both central (Aguayo et al., 1982) and peripheral (Simpson and Young, 1945) axons can readily regenerate along degenerated peripheral nerve pathways, reminiscent of their initial outgrowth in the developing animal. Since collateral sprouting and regeneration can 
be selectively evoked in the adult, their growth factor dependency can be studied separately. The findings might give insights into the comparable axonal growth states during development, as well as their character and significance in the adult.

The present report deals with the role that NGF could play in the collateral sprouting of cutaneous sensory nerves. An approach that has proved rewarding for the study of such sprouting in the adult rat utilizes the "isolated field" preparation (Jackson and Diamond, 1984; Nixon et al., 1984; Doucette and Diamond, 1987). With this experimental paradigm, we have investigated, first, whether a maintained regime of anti-NGF administration would prevent the collateral sprouting of undamaged nociceptive nerves and, second, whether exogenously administered NGF would evoke such sprouting. A reexamination has also been made of some earlier findings showing that centrally conducted impulses can markedly accelerate the collateral sprouting of these cutaneous nerves ("precocious sprouting"; Nixon et al., 1984; Doucette and Diamond, 1987). The rcsults point to an intriguing interaction between the effects of impulses and of endogenous NGF, an interaction that could be involved in plasticity and learning. In the following companion article (Diamond et al., 1992), we describe some analogous studies of the regeneration of sensory nerves, with unexpectedly different results.

A preliminary account of some of these findings has been reported (Diamond et al., 1987).

\section{Materials and Methods}

\section{Preparation of NGF and its antiserum}

2.5S NGF was prepared from male mouse salivary glands according to the method of Mobley et al. (1976) and further purified by gel filtration on a Sephadex G-75 column $(0.7 \times 90 \mathrm{~cm})$ in $2 N$ acetic acid (Darling and Shooter, 1984; Mobley et al., 1985). Electrophoresis of the 2.5S NGF in a $16 \%$ polyacrylamide gel containing sodium dodecyl sulfate (SDS-PAGE) showed the only stained bands (silver stain) to be the usual doublet at $13.5 \mathrm{kDa}$ with some minor diffuse staining at the buffer front (probably degradation products). Neuronotrophic biological activity was measured in the dissociated cell assay (Greene, 1977) using neonatal mouse superior cervical ganglion (SCG) neurons (Coughlin and Collins, 1985); half-maximal response was at $1 \mathrm{ng} / \mathrm{ml}$. 7S NGF was prepared according to a modification (Stach et al., 1977) of the procedure of Varon et al. (1967), and also displayed half-maximal activity in the dissociated cell assay at $1 \mathrm{ng} / \mathrm{ml}$.

For the preparation of NGF antiserum (anti-NGF), both white New Zealand rabbits and sheep (ewes) were used, providing results that were essentially indistinguishable. These animals received an initial injection of $0.5 \mathrm{mg}$ of $2.5 \mathrm{~S} \mathrm{NGF}$; the NGF in phosphate-buffered saline was mixed with 2 vol of Freund's complete adjuvant and injected intradermally at 20-30 sites. After 4 weeks, boosting doses of 2.5S NGF in Freund's complete adjuvant were given intradermally at multiple sites, $0.1 \mathrm{mg}$ for the rabbits and $0.5 \mathrm{mg}$ for the sheep. Thereafter, monthly boosts of these amounts of 2.5S NGF were made in Freund's incomplete adjuvant. Blood was collected from the ear veins of the rabbits and jugular veins of the sheep, beginning $10 \mathrm{~d}$ after the second boost. Blood was allowed to clot at room temperature. Serum was collected, heat inactivated at $56^{\circ} \mathrm{C}$ for $30 \mathrm{~min}$, cooled, and filter sterilized.

To determine serum titers of anti-NGF, serial dilutions of the antiserum in culture medium were combined with equal volumes of medium containing $20 \mathrm{ng} / \mathrm{ml} 7 \mathrm{~S} \mathrm{NGF}$ (final concentration, $10 \mathrm{ng} / \mathrm{ml} 7 \mathrm{~S} \mathrm{NGF}$ ), incubated at room temperature for $1 \mathrm{hr}$, and assayed by the dissociated cell method, as above. A 10,000-fold dilution of antiserum completely blocked the activity of $10 \mathrm{ng} / \mathrm{ml} 7 \mathrm{~S}$ NGF.

Specificity of the antibody was determined by the Ouchterlony double-diffusion analysis and by Western blot. Antiserum to NGF gave single precipitin lines with the crude salivary gland homogenate and with the post-acid precipitation fraction, as well as with purified 7S and 2.5S NGF. For Western blots, the IgG fraction of antiserum was isolated by ammonium sulfate precipitation and labeled with ${ }^{125}$ I (Greenwood et al., 1963). Proteins were run on SDS-PAGE as above, and then transferred to nitrocellulose paper (Towbin et al., 1979) and incubated with labeled anti-NGF (Burnette, 1981). The only bands labeled by the anti-NGF were the $13.5 \mathrm{kDa}$ bands in the lanes corresponding to $2.5 \mathrm{~S}$ NGF, 7S NGF, and the salivary gland homogenate. No antibodies bound to mouse serum proteins, renin, or epidermal growth factor.

\section{Administration of antibody serum and control serum}

Rats were injected subcutaneously, in the nape of the neck or in the loose skin of the groin. A standard daily dosage was arrived at from preliminary studies; this was $2.5 \mu \mathrm{l} / \mathrm{gm}$ body weight, a regime well tolerated by the animals. As additional observations were made, this routine dosage turned out to be some $30-40 \%$ higher than the minimum effective dosage (see Results).

\section{Operative procedures to produce the "isolated sensory field"}

These procedures were similar to those described in Doucette and Diamond (1987). Female Wistar rats between 200-270 gm, but occasionally smaller, were anesthetized with an intraperitoneal injection of 45 $\mathrm{mg} / \mathrm{kg}$ sodium pentobarbital. Body temperature was maintained by a heating pad. The fur was clipped from the skin of the thoracolumbar region of the back, and a $4-5 \mathrm{~cm}$ incision was made approximately 1 $\mathrm{cm}$ to the right of the midline. Gentle lateral tension exposed the array of dorsal cutaneous nerves (DCNs). For permanent elimination of selected DCNs, these nerves were stretched out of their site of emergence from the body wall with a pair of fine watchmaker's forceps and cut at this point, thereby allowing the central stump to withdraw behind the muscle. In addition, the entire dorsal portion of the nerve (some 2-3 $\mathrm{cm}$, almost to the skin) was excised. These procedures successfully disallowed nerve regeneration to the skin in almost every instance. The thoracic (T) DCNs 9-12, the lumbar (L) DCNs 1-3, and the lateral cutaneous nerves T10-T13 and L1-L3 were removed on the left side, leaving only DCN T13 intact. The lateral of the two branches of DCN T13 was then carefully freed of connective tissue, cut a few millimeters from the body wall, and ligated, and the central stump was buried deep under the latissimus dorsi muscle. DCNs T11-L2 on the right side were all similarly eliminated. The skin was sutured using a continuous catgut thread. This procedure left the medial branch of DCN T13 (mDCN T13) intact on the left side, with its sensory field "isolated" within a relatively vast surround of denervated skin. The animal was protected against infection by an intramuscular injection of a long-acting penicillin/streptomycin-based antibiotic. Incidence of overt infection was very low.

\section{Behavioral mapping of the nociceptive fields}

Mapping was performed under light sodium pentobarbital anesthesia $(30-35 \mathrm{mg} / \mathrm{kg})$, a level that left brisk but localized reflex responses to pinching of the skin or foot. Mechanonociceptive ("pinch") fields were mapped with a pair of fine-toothed forceps with a tip of about $0.35 \mathrm{~mm}$, and heat-nociceptive ("heat") fields, with a probe of copper heated by a resistance wire, which had a flat tip providing approximately $1-2 \mathrm{~mm}^{2}$ of contact area. A thermistor buried within the tip of the probe provided a continuous measurement of its temperature, which was maintained between $63-67^{\circ} \mathrm{C}$; this was just bearable to the hand, and over the very few seconds of its application produced no visible damage to the rat skin. In order to improve heat transfer, and so reduce probe application times, the skin was dampened with a moist cotton swab before and during testing.

Application of either of these noxious stimuli to the skin reflexly activates the cutaneus trunci muscle (CTM), causing a distinct and maintained puckering of the skin both close to the area of stimulation and on the corresponding contralateral area (Theriault and Diamond, 1988). The borders between the sensitive and insensitive areas of the skin were determined (to within about $1 \mathrm{~mm}$, with practice) by the respective presence or absence of the CTM response to successive applications of the stimulus at approximately $2-3 \mathrm{~mm}$ intervals (Nixon et al., 1984). A fine-tipped waterproof fiber pen was used to mark the skin between unresponsive test sites and responsive neighboring sites. The procedure, repeated radially around a skin field, defined the particular nociceptive border (heat, pinch, or touch; see below).

\section{Light touch field mapping (Jackson and Diamond, 1984)}

The low-threshold mechanosensory ("touch") field was delineated electrophysiologically. The dissected-free and cleaned nerve trunk was laid 


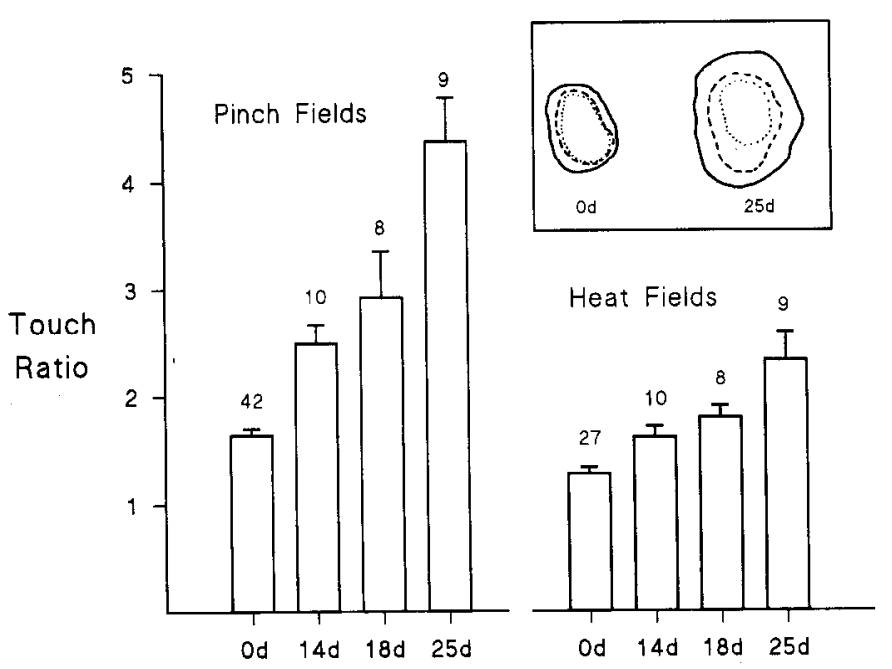

Figure 1. Expansion of the mDCN T13 fields into surrounding denervated skin following their "isolation." The inset shows a typical example from one animal of the fields measured immediately following their isolation $(0 d)$ and from a second animal that was first mapped 25 $\mathrm{d}$ after field isolation. The "touch" field is dotted, the "heat" field dashed, and the "pinch" field is the continuous line. In this figure, and in Figures $3,4,5 A$, and 6 , the ordinate shows the "touch ratio," that is, the ratio nociceptive field : touch field ( \pm SEM), used as the measure of the nociceptive fields (see Materials and Methods). The postisolation times when the fields were measured are indicated along the abscissae (which are not scaled). The value above each histogram, in this and subsequent figures, is the number of animals in the group. The $0 d$ pinch field group included some animals whose heat fields were not measured; the other animals provided both pinch and heat ficld data. Each group of animals provided the data at only one postisolation time.

across bipolar platinum wire electrodes feeding into the input of a differential AC preamplifier, the output of which was displayed on a Tektronix storage oscilloscope and an audio amplifier. The brushing of innervated skin with a fine bristle evoked clearly audible responses, which disappeared abruptly as the stimulus crossed the touch field border.

When a field had been isolated and defined, a few spots were tattooed into the skin, some 7-8 $\mathrm{mm}$ outside its border, by puncturing the skin with a 27 gauge hypodermic needle dipped in India ink. These spots provided reference points to be used in the comparison of field mappings done at later times. To make permanent records, a sheet of transparent acetate was placed over the skin of the rat and the positions of the field borders and the reference tattoos were transferred to it with waterproof colored markers. Areas of the fields were determined with an image analyzer (Bioquant).

\section{Evaluation of normal and precocious collateral sprouting}

The progressive expansion of the nociceptive fields of the medial branch of the selected dorsal cutaneous nerve (mDCN T13), following denervation of the surrounding skin (Fig. 1), has been shown to be attributable to collateral sprouting of the A $\delta$-fibers (for the pinch field) and the C-fibers (for the heat field) (Nixon et al., 1984; Doucette and Diamond, 1987). To measure normal sprouting, rather than the earlier-appearing precocious sprouting that would occur if the fields were mapped immediately following their isolation (see below), advantage was taken of the knowledge that the A $\alpha$-fibers subserving light touch do not sprout in adult rats (Jackson and Diamond, 1984), and that each of the nociceptive fields bears a proportional relationship to the touch field (Nixon et al., 1984; Doucette and Diamond, 1987). As in the latter studies, normal nociceptive field expansion was thus measured by the increase in the value of the nociceptive field : touch field ratio.

In experiments on precocious sprouting, both of the nociceptive fields were measured immediately following their isolation. The mapping procedure evokes volleys of centrally conducted impulses in the nociceptive fibers, and it is these impulses that accelerate the onset of sprouting (Nixon et al., 1984; Doucette and Diamond, 1987). Subsequent map- pings then allowed the changes of field sizes to be identified directly, relative to their initial values.

\section{Evans blue test for sensory $C$-fibers}

Evans blue (5\% in $0.9 \%$ saline) was injected intravenously into the anesthetized animals at a dosage of $50 \mathrm{mg} / \mathrm{kg}$, and a period of $10 \mathrm{~min}$ was allowed for the areas of nonelectrogenic extravasation of the circulating (protein-bound) dye to become apparent (Kenins, 1981). The nerve was then lifted onto platinum wire electrodes and stimulated with $1 \mathrm{msec}$ square pulses at $20 \mathrm{~Hz}$, with intensities up to $15 \mathrm{~V}$ [suprathreshold for the C-fiber-evoked CTM reflex (Doucette and Diamond, 1987)]. The direction of the pulses was reversed intermittently, and the stimulation periods (lasting a few seconds) were alternated with similar "rest" periods. The entire period of stimulation, including rest periods, was $10-15 \mathrm{~min}$. After this time, the blue extravasation in the skin was well developed and appeared as a mottled blue patch, sometimes easily seen to consist of individual spots. In normal animals, the blue staining is coextensive with the behaviorally measured heat field, even when this field has expanded by collateral sprouting (Doucette and Diamond, 1987).

\section{Intradermal NGF injections}

Injections of NGF or, as a control, of cytochrome C (various doses, in $0.1 \mathrm{ml}$ of phosphate buffer, $\mathrm{pH} 7.2$ ), were made via a 27 gauge needle. When the injections were made into skin innervated by the nerve under study, the needle was first inserted through the full skin thickness at a location just outside the border of the identified touch field of the nerves, and the tip was then directed so as to penetrate up into the dermis at a point just within the border of the field. Usually, the daily dose was divided among three injection sites located within the posterolateral zone of the isolated field. In some experiments the injections were made into skin on the opposite side of the midline.

\section{Morphological examinations}

Silver staining of axonal pathways in the dermis. Loots silver method (Loots et al., 1979) was modified for frozen sections. Pieces of back skin (approximately $1 \mathrm{~cm}^{2}$ ) were excised, spread flat on a piece of cork, and plunged into liquid nitrogen-cooled isopentane. Samples were usually stored at $-80^{\circ} \mathrm{C}$ before sectioning. Serial cryostat sections ( $30 \mu \mathrm{m}$ thick) were collected on slides, fixed with neutral-buffered $10 \%$ formalin for $1-4 \mathrm{hr}$, and then denatured in $80 \%$ ethanol before incubation in Loots protargol-peroxide solution. After reduction and silver intensification, sections were fixed in hypo ( $2 \%$ sodium thiosulfate), dehydrated, cleared, and mounted.

Electron microscopy (EM). Skin samples were immersed in fixative ( $2.5 \%$ glutaraldehyde, $2 \%$ paraformaldehyde, $2.5 \%$ dimethyl sulfoxide in $0.1 \mathrm{M}$ sodium phosphate buffer, $\mathrm{pH} 7.3$ ) and kept overnight at room temperature. Postfixation employed $2 \%$ osmium tetroxide and $1 \%$ potassium dichromate in $0.1 \mathrm{~m}$ sodium phosphate buffer, $\mathrm{pH}$ 7.3. Samples were stained en bloc with $1 \%$ uranyl acetate in $0.1 \mathrm{M}$ sodium acetate buffered solution ( $\mathrm{pH} 7.2$ ), dehydrated with ascending grades of acetone and infiltrated and embedded in Spurr's epoxy resin (Spurr, 1969). Sections were cut on a Reichert-Jung Ultracut E ultramicrotome. Thick sections $(0.5-1 \mu \mathrm{m})$ were stained with a $1 \%$ toluidine blue and $1 \%$ borax solution, while thin sections (approximately $85 \mathrm{~nm}$ ) were grid stained with 3\% uranyl acetate in 50\% ethanol and Reynolds' lead citrate (Reynolds, 1963), and viewed on a JEOL 1200 EX or Philips EM 301 transmission electron microscope.

\section{Results}

\section{The time course and pathways of collateral sprouting in normal skin}

Figure 1 shows that in normal rats both the pinch and the heat fields have begun to increase significantly by 2 weeks following isolation of their fields, and that by $25 \mathrm{~d}$ (when the expansion has slowed markedly), they have more than doubled their initial areas. We confirmed (Fig. 2) our earlier observations that (1) within a few days of denervation, the silver-stainable axons, normally segregated within the dermal perineurial tubes, disappear from these tubes in the skin surrounding an isolated nociceptive field; (2) as the field expands, axons progressively 

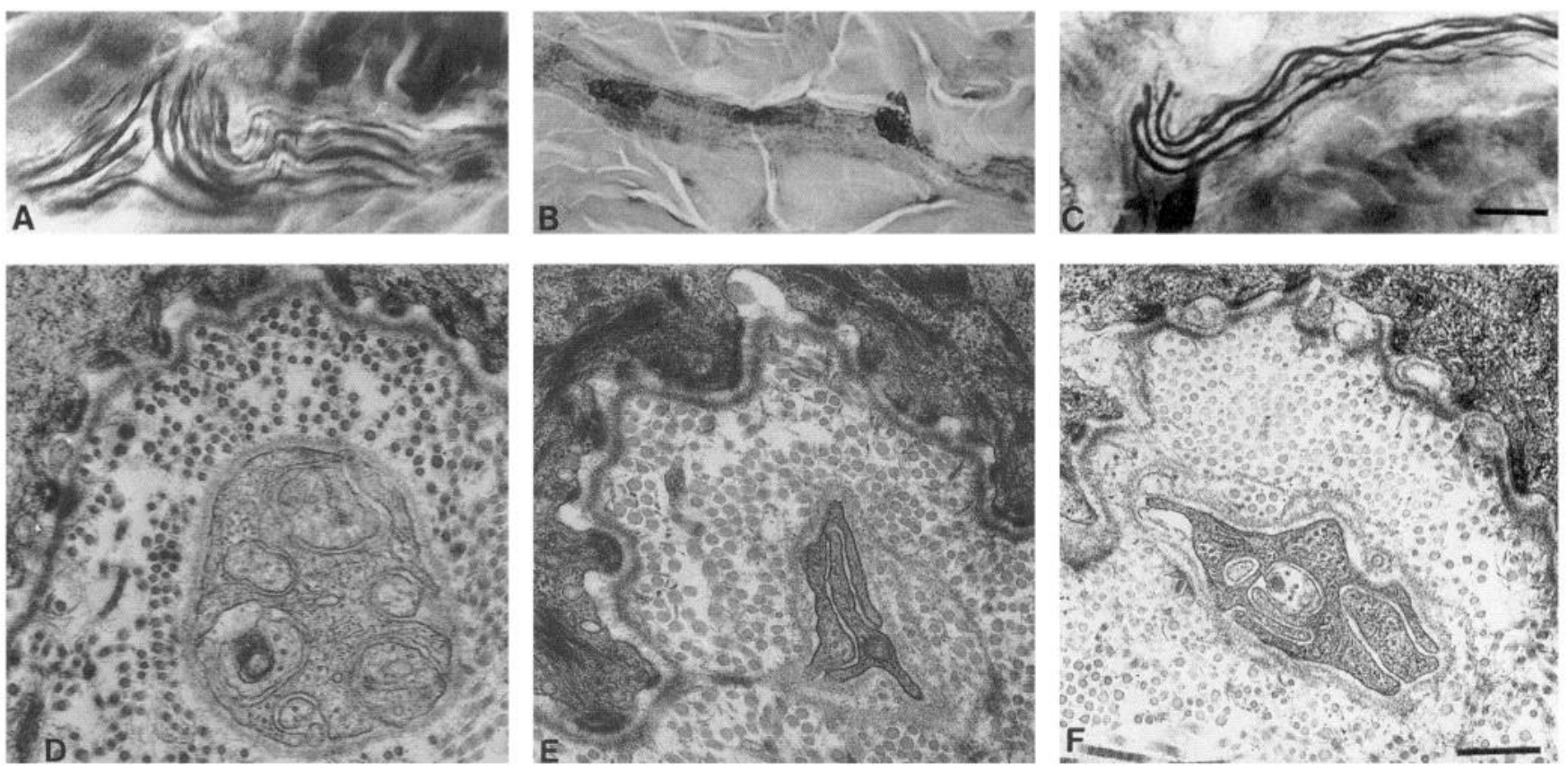

Figure 2. Morphological demonstration that anti-NGF treatment blocks collateral sprouting. $A-C$ show light micrographs of dermis. $A$ came from a normal rat and shows silver-stained axons within the perineurial tubes; $B$ is from skin taken just outside an innervated field that had been isolated $25 \mathrm{~d}$ earlier and prevented from expanding by anti-NGF treatment-the perineurial tube is devoid of axons; $C$ came from a region corresponding to that in $B$, but from an untreated animal in which the field, isolated $25 \mathrm{~d}$ earlier, had expanded in the usual way-the expansion was correlated with the reappearance of axons in the perineurial tubes, as shown here. $D-F$ are electron micrographs of the horizontal subepidermal C-fiber network in the same skin regions, respectively, of $A-C$. In $D$ (normal skin) a typical bundle of C-fibers is present within an epidermal gutter (see Results). In $E$ (insensitive skin) there is only a Schwann tube, devoid of axons. In $F$ (the region of field expansion) the Schwann tube now contains typical unmyelinated axon profiles. Scale bars: $C$ (for $A-C$ ), $20 \mu \mathrm{m} ; D$ and $E, 0.5 \mu \mathrm{m} ; F, 1.0 \mu \mathrm{m}$.

reappear in the perineurial tubes; (3) the bundles of sensory C-fibers, which are seen with EM to run in the horizontal subepidermal network, also disappear after denervation; and (4) field expansions are associated with the reappearance of C-fibers in some (although by no means all) of the vacated Schwann tubes of this network. An additional observation was that the unmyelinated fiber bundles, normally seen with EM to run alongside myelinated axons within the dermal perineurial tubes, also reappeared in these pathways (along with thinly myelinated axons) when the skin recovered its responsiveness to nociceptive stimuli. Axons were rarely observed outside of these two perineurial pathways, whether in normally innervated skin or skin that had become reinnervated by collateral sprouting. Occasionally, silver staining revealed sporadic single axons usually running close to the deeper dermal pathways. Our EM studies of serial sections often revealed a fusing of the basal lamina surrounding a $\mathrm{C}$-fiber bundle with the basal lamina separating the epidermis and the dermis (Doucette and Diamond, 1987); such a nerve bundle, therefore, ultimately comes to lie within the basal cell layer of the epidermis, coincidentally confirming the sensory nature of these axons (there are no autonomic targets in the epidermis; cf. Cauna, 1969; Kruger et al., 1981). Other sensory fibers presumably leave the major perineurial tubes to terminate within the dermis proper, including, for example, the hair follicles (Millard and Woolf, 1988).

\section{The effects of anti-NGF administration on the collateral sprouting of nociceptive fibers}

Beginning on the day of field isolation, antiserum to NGF was administered every day to one group of animals and nonimmune

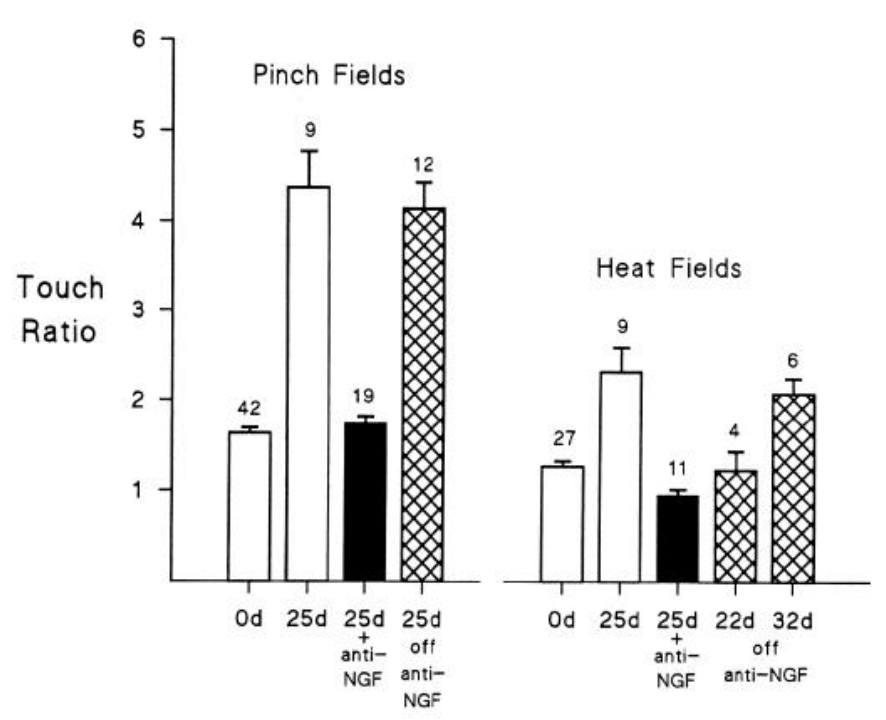

Figure 3. Prevention of collateral sprouting by anti-NGF treatment, and its recovery after treatment ends. The $0 d$ and $25 d$ open histograms show, respectively, the initial and final sizes of the isolated pinch and heat fields of animals that were injected daily with nonimmune serum. The solid histograms show the results at $25 \mathrm{~d}$ for similarly prepared animals that received a daily injection of anti-NGF serum, as described in Results. Treatment was then stopped in 12 of the animals used for the pinch field data and 6 of those used for the heat field data; $25 \mathrm{~d}$ later (crosshatched histograms) the pinch fields had sprouted to their usual extent ( $25 d$ off anti-NGF histogram), while the heat fields, measured at two times (four measured at $22 \mathrm{~d}$ and all six measured at 32 d) following cessation of treatment, took longer ( $32 \mathrm{~d})$ to reach their usual extent of sprouting. Other conventions as noted in Fig. 1. 


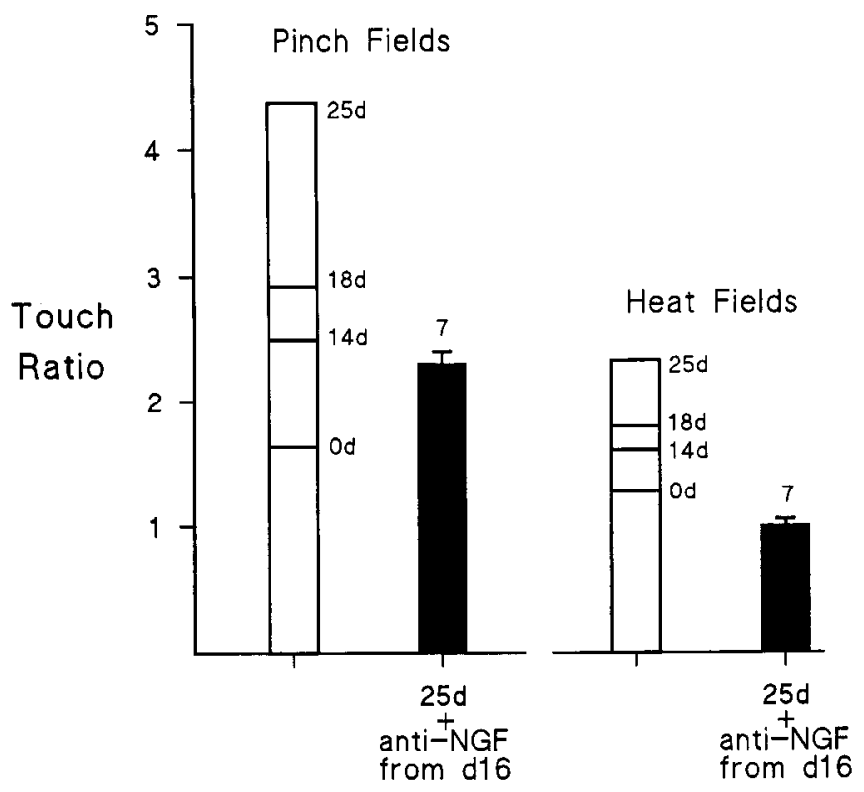

Figure 4. Anti-NGF treatment halts sprouting already in progress. The four open histograms for both pinch and heat show the sizes (mean values only are shown) of the isolated fields, at the postisolation intervals indicated alongside $(0,14,18$, and $25 \mathrm{~d}$; data of Fig. 1). In the seven animals represented by the solid histograms, the fields were similarly isolated, but anti-NGF treatment was not started until $16 \mathrm{~d}$ had elapsed. The field sizes were measured $9 \mathrm{~d}$ later, that is, a total of $25 \mathrm{~d}$ after field isolation, as indicated below the respective histograms. Comparison of the sizes of the fields measured in these seven animals at that time, with their sizes when the treatment was started (which would have been roughly midway between the respective $14 \mathrm{~d}$ and $18 \mathrm{~d}$ values) shows that they must not only have stopped expanding fairly soon after the onset of treatment, but actually have shrunk; the expansion of the heat field in particular appeared to have been totally eliminated (see Materials and Methods).

serum to a control group. The results from the latter group did not differ detectably from those described above for normal untreated animals. However, a striking difference was found in the anti-NGF-treated animals; their nociceptive fields had failed to expand (Fig. 3), and, indeed, the heat field appeared actually to have shrunk somewhat, an observation that is currently being extended (see Diamond et al., 1988). This lack of field expansion was not attributable to the failure of sproutcd axons to bccomc functional; when anti-NGF-treated animals were examined 25 $\mathrm{d}$ after the isolation procedure, no nerve fibers were detected in the skin $>1-2 \mathrm{~mm}$ outside the nociceptive field, within either the deeper perineurial tubes or the subepidermal network (Fig. $2 A, B, D, E)$. In animals not subjected to the anti-NGF regime, axons reappeared in both of these pathways within the skin that had coincidentally recovered nociceptive function (Fig. $2 C, F$ ). However, many of the subepidermal Schwann tubes remained axon free. The absence of sensory $\mathrm{C}$-fiber sprouting in the antiNGF-treated animals was also indicated by the absence of expansion of the "Evans blue field" (cf. Doucette and Diamond, 1987 , and Materials and Methods), although in the treated animals these fields were less well defined than in the controls.

The blocking of collateral sprouting of both the $\mathrm{A} \delta$ and $\mathrm{C}$ nociceptive fibers by the anti-NGF treatment was fully reversible (Fig. 3). Following ccssation of the injections, the pinch fields had expanded close to their normal maximum by a further $25 \mathrm{~d}$, the heat fields taking longer, possibly because their expansion began from a smaller than normal field size. In one group of animals, the daily anti-NGF injections were not begun until $16 \mathrm{~d}$ after isolation of the field; that is, treatment was delayed to a time when collateral sprouting is normally well established. Measured at the usual $25 \mathrm{~d}$ postisolation, the size of the pinch field was found to be less than it must have been at the onset of treatment (Fig. 4), while the expansion of the heat field appeared to have been completely abolished. These intriguing findings are being examined further (Diamond et al., 1988).

\section{The effects of NGF administration}

We attempted to evoke collateral sprouting directly by the $\mathrm{cu}$ taneous administration of purified NGF protein. Three different protocols were used. In each of these protocols the total daily dosage of NGF was $50 \mu \mathrm{g}$, administered as three or four intradermal injections at different locations within the selected field (see Materials and Methods). Cytochrome $\mathrm{C}$ injections were given to control animals.

In the simplest protocol, daily injections were given for $7 \mathrm{~d}$ into normally innervated skin. On the first occasion, however, the skin was also pinched some 50-100 times to provide the conditioning stimulation known to evoke precocious sprouting, in which the latency to onset of sprouting is reduced by some 5-6 d (see section 4 below). The nerve field was then isolated by surrounding denervation, and its two nociceptive fields and touch field were mapped. The ratio approach (see Materials and Methods) was used to evaluate whether any nociceptive field expansions had occurred. No differences were found for the touch fields between experimental and control animals, their mean values being within the range found in normal animals of similar size and age. However, both the mechano- and the heat-nociceptive fields in the NGF-treated animals had expanded significantly relative to the controls (Fig. 5A); that is, collateral sprouting had occurred in this instance into the adjacent normally innervated skin. In the second approach, daily injections of NGF were begun on the day that the nerve fields were isolated and mapped, and continued throughout the experiment. The sprouting was thus precocious, as mentioned above, but the exogenous NGF was administered against a background of (presumably; see below) increasing endogenous NGF levels. The rates of the nociceptive field expansions were significantly increased by the NGF injections; the result was especially marked for the pinch fields, as shown in Figure $5 B$. In one of the four NGF-treated animals there was an abnormal bulge on one aspect of both the pinch and the heat fields. In the third protocol the animals were maintained on a reduced antiNGF regime ( $50 \%$ of the routine dosage), which decreased the normal collateral sprouting to a low level. This treatment was started immediately after field isolation and mapping. At about 5-7 d postisolation, when precocious sprouting normally becomes detectable, the daily injections of NGF were begun, and continued in this experiment for $9 \mathrm{~d}$. The results were similar for both nociceptive fields and showed that NGF produced an increase in their initial rates of expansion; Figure $5 C$ illustrates the findings for the pinch fields.

In none of the above studies did NGF administration cause any detectable sprouting of the low-threshold $\mathrm{A} \alpha$-fibers.

We had expected that nociceptive field expansions might be morc pronounced in the vicinity of the NGF injections, but except for the instance mentioned above, this was not observed. One possibility was that NGF, like anti-NGF, did not need to be injected locally to be effective. Consequently, in a few further 
experiments, which followed the second protocol described above, the daily NGF injections were delivered to the skin on the opposite side to that in which the fields had been isolated. Some $15 \mathrm{~d}$ later, both the mechano- and heat-nociceptive fields were found to have enlarged to a greater extent in the NGFtreated animals than in the controls, while the touch fields were of normal size. Thus, systemic administration of NGF was effective in evoking sprouting in skin regions remote from the injection locus.

\section{Impulse priming of collateral sprouting}

$A$ role for endogenous $N G F$. In the precocious sprouting paradigm, the time to onset of sprouting following adjacent denervation is reduced by about $5-6 \mathrm{~d}$ if the isolated field is mapped initially. This reduction is attributable to the impulses evoked by the physiological testing procedures (pinch or heat) (Nixon et al., 1984; Doucette and Diamond, 1987). Isolated touch fields remain unchanged after skin stimulation (Nixon et al., 1984). In the present experiments, precocious sprouting was prevented by the same anti-NGF treatment that blocked normal sprouting (e.g., Fig. 9). To examine whether the action of the conditioning impulses per se is also dependent on the availability of endogenous NGF, the impulses were evoked during an "umbrella" of anti-NGF treatment. We utilized two findings: first, that antiNGF injections are rapidly effective (Fig. 4), and second, that precocious sprouting can still be evoked even when the conditioning stimulation is given up to $2 \mathrm{~d}$ prior to field isolation (Nixon et al., 1984). To create the umbrella, two anti-NGF injections were given, the first on the day preceding and the second on the same day as the conditioning stimulation. Control animals received similar injections of nonimmune serum. The conditioning stimulation utilized some 50-100 forceps pinches of the region known to be supplied by the mDCN T13, specifically the flank skin posterior to the rib border, anterior to the pelvis, and extending to the midline. One day after conditioning, the fields were isolated in the usual way. In order to avoid giving a second conditioning volley of impulses, the fields were not mapped at that time, and instead the nociceptive field : touch field ratio (see Materials and Methods) was used to detect the subsequent occurrence of collateral sprouting. This was exam-

Figure 5. NGF evokes collateral sprouting. This experiment utilized the precocious sprouting paradigm, as described in the text. $A$ shows the sizes of the pinch and heat fields, which were isolated and measured (as touch ratios) $7 \mathrm{~d}$ after beginning daily intradermal injections of either NGF (hatched histograms) or cytochrome C (open histograms). The fields were of normal size in the control animals, but NGF had evoked significant sprouting into the adjacent normally innervated skin. $B$ shows the expansions (due to precocious sprouting) of the pinch fields in two groups of animals, one of which received daily injections of NGF beginning on the day of field isolation, while the other (control group) received injections of cytochrome $\mathrm{C}$. In the NGF-treated group the rate of field expansion (increase relative to the normalized value of the initial mean field size of the group) was enhanced; the area increase at day 14 was significantly greater than the corresponding con trol value $(p<0.03)$. $C$ shows the effects of daily NGF administration that was started $6 \mathrm{~d}$ after (precocious) collateral sprouting was initiated by field isolation and testing (arrow). However, in this experiment, a concomitant anti-NGF treatment was used to hold the usual sprouting to a low level (here shown for the control animals that received cytochrome $C$ injections; see Results). The ordinate shows the pinch field sizes normalized to that measured on the day of the first NGF or cytochrome Cinjection for each animal ( \pm SEM). The experiment was terminated $9 \mathrm{~d}$ later $(15 \mathrm{~d}$ postisolation). The initial rate of sprouting following the onset of NGF ad-
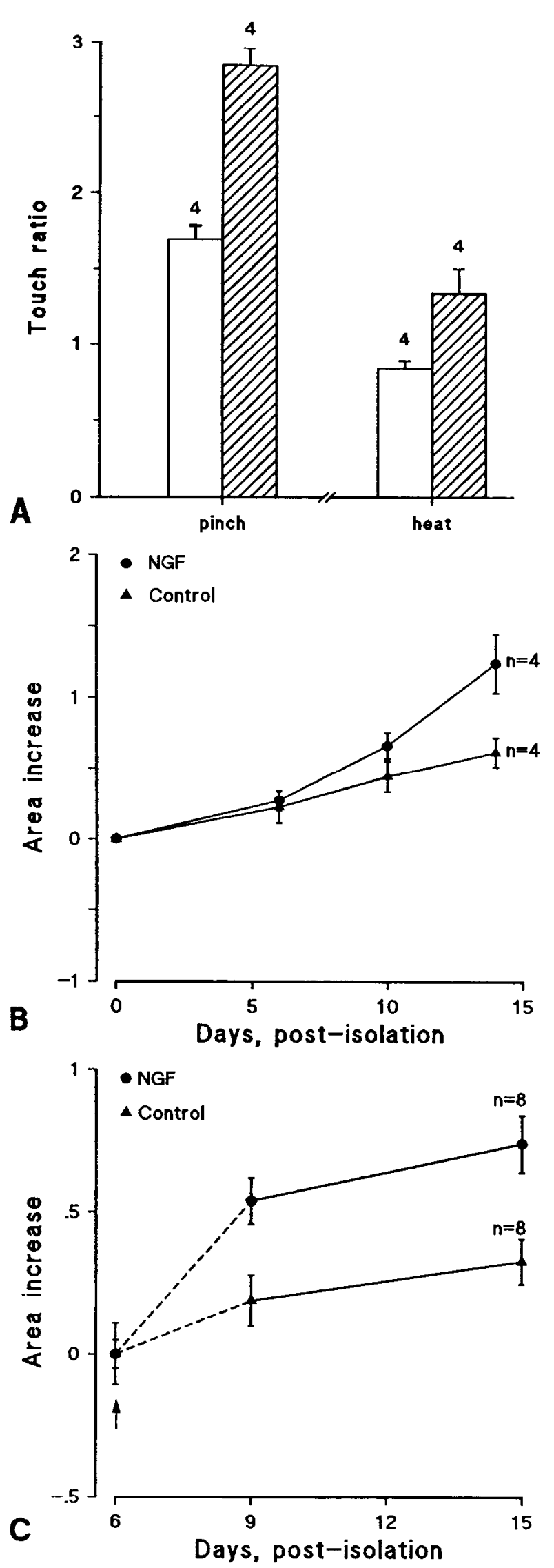

ministration was clearly increased, although it is uncertain when this increase started (the points between 6 and $9 \mathrm{~d}$ are dashed to indicate this). 


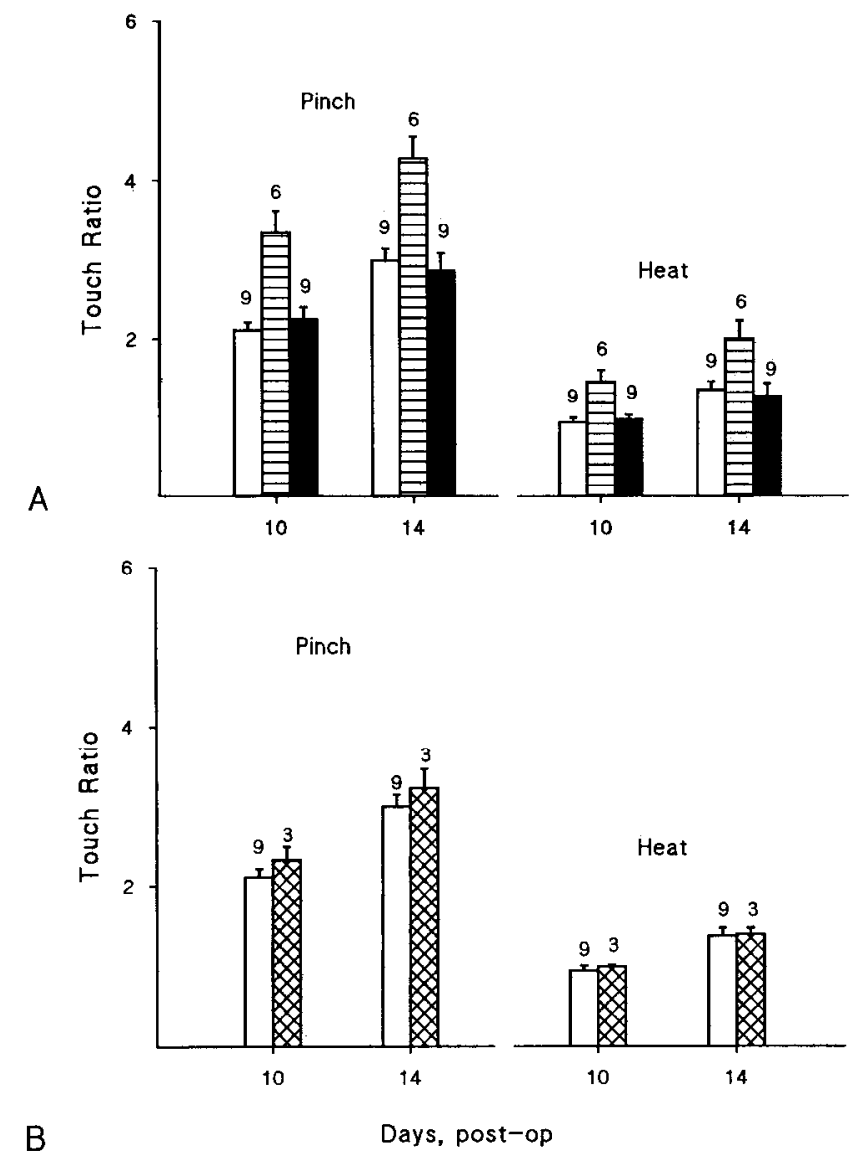

Figure 6. The precocious sprouting paradigm: impulses are effective only in the presence of normal endogenous NGF levels. The touch ratios were used to measure pinch and heat field sizes at 10 and $14 \mathrm{~d}$ after their isolation. Normal sprouting had reached just-detectable levels by $10 \mathrm{~d}$, but precocious sprouting was well advanced. By $14 \mathrm{~d}$, when "unconditioned" sprouting was very apparent, precocious sprouting was approaching its ceiling. $A$ shows the results from three groups of animals: one group received conditioning pinches $1 \mathrm{~d}$ prior to field isolation, done under an "umbrella" of control serum as explained in Results (striped histograms); a second group was treated similarly, but with an anti-NGF umbrella (solid histograms); the third group (open histograms) received neither pinches nor injections and represented the normal (unconditioned) sprouting paradigm. Clearly, precocious sprouting had occurred in the first group; however, the anti-NGF umbrella abolished the effects of the conditioning stimulation so that the sprouting (solid histograms) reverted to the time course of the unconditioned sprouting (open histograms). B shows that the two injections which constituted the anti-NGF umbrella did not affect sprouting per se. The results shown here came from animals that received no conditioning stimulation, either prior to or after field isolation. The animals represented by the crosshatched histogram received an anti-NGF "umbrella" consisting of two injections timed to occur at 6 and $7 \mathrm{~d}$ prior to the anticipated onset of normal sprouting, as explained in Results. (The injections given in the experiment of $A$ were similarly given in advance of the anticipated sprouting, in that instance, however, precocious sprouting.) In the group represented by the open histograms no injections were made. In both groups of animals the sprouting was of the normal time course. AntiNGF injections made at even earlier times (e.g., 1-2 d prior to field isolation as in $A$ ) were similarly ineffective.

ined $10 \mathrm{~d}$ after field isolation, when precocious sprouting would normally be well advanced but unconditioned sprouting would hardly be detectable (Doucette and Diamond, 1987). The results (Fig. 64) showed that in the animals in which the conditioning was done under the $2 \mathrm{~d}$ umbrella, the precocious sprouting was

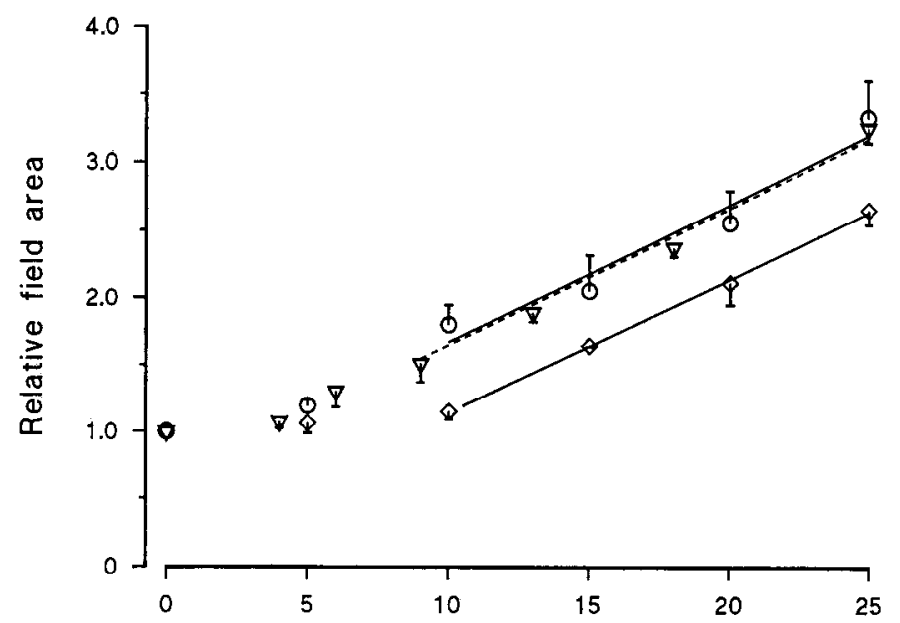

Days, post-isolation

Figure 7. Impulses affect only the latency and not the rate of sprouting. The time course of collateral sprouting in three different experimental situations is shown. The diamonds are normal (unconditioned) sprouting data, and the value at each time point came from an individual group of animals that was examined once only, at the indicated time. The touch ratio was used as the measure of nociceptive field size, and all values were normalized to that at $0 \mathrm{~d}$, that is, to the touch ratio for the respective nociceptive fields measured immediately postisolation. The circles and the triangles are data from animals whose fields were measured soon after their isolation, and refer, therefore, to precocious sprouting. The fields were normalized to those measured initially. Error bars are \pm SEM. The animals that provided the data indicated by the circles were mapped a second time only, in a terminal experiment done at the time indicated. The triangles are data from animals that were mapped repeatedly, at the times indicated. It is clear that conditioning stimulation affected only the latency of sprouting; its rate was similar in the normal and precocious sprouting paradigms, even when stimulation was repeatedly applied during the sprouting phenomenon.

absent; the sprouting that did subsequently appear had an essentially normal latency.

The possibility was examined that the $2 \mathrm{~d}$ anti-NGF treatment might itself have delayed the onset of sprouting, thereby offsetting the accelerating action of the conditioning impulses in the preceding experiment. Had precocious sprouting occurred in the usual way, it would have been detected some 6-8 d after the second anti-NGF injection (see below). We therefore set up the normal sprouting paradigm, that is, without conditioning impulses, and inserted two anti-NGF injections, timed to be at 6 and $7 \mathrm{~d}$ prior to the predicted onset of observable sprouting (which would normally be 10-12 d after the field was isolated). The results showed no detectable effects of the injections; sprouting had not begun at $10 \mathrm{~d}$, but had reached its usual levels by $14 \mathrm{~d}$ (Fig. 6B). Other indications that the effects of anti-NGF injections would have disappeared by $6 \mathrm{~d}$ came from the doseresponse studies described below.

Is the rate of sprouting increased by impulses? In light of the new finding implicating endogenous NGF in the conditioning action of impulses, and of the demonstration that precocious sprouting, like normal sprouting, is NGF dependent, we examined the possibility that the repeated generation of impulses during sprouting might increase its rate. Three groups of animals were studied. In the first group the fields were isolated, and to avoid generating conditioning impulses, the fields were mapped only once, in a terminal experiment done at a selected time 
postisolation. The nociceptive field expansions were estimated from the nociceptive field : touch field ratio, as explained above. In the second and third groups, the nociceptive fields were measured soon after they were isolated; that is, the precocious sprouting paradigm was used. However, while the animals of one of these groups were reexamined once only, at a terminal experiment as in the first group, the nociceptive fields in the remaining group were repeatedly tested (every $3-5 \mathrm{~d}$ ), thereby generating an additional train of afferent impulses on each occasion. The results (Fig. 7) showed no significant differences among the groups with respect to the mean rates of expansion over the periods when this was at its maximum (when it was also relatively linear). Thus, the normal rate of sprouting is unaffected by impulses, although as described above, it can be increased by exogenous NGF.

\section{How much of the latency to sprouting onset is occupied by} buildup of NGF in the denervated skin?

When the latency of precocious sprouting is corrected as described in the Discussion below, it reduces to as little as $2-3 \mathrm{~d}$. Since this time includes that required for the nerve to initiate sprouting in response to $\mathrm{NGF}$, it represents the upper limit of the time for endogenous NGF in the skin to reach effective levels. To clarify this point further, two experiments were done.

(1) Sprouting latency after removal of anti-NGF block. If this latency were similar to that of normal precocious sprouting, it would suggest (other things being equal, as discussed below) that the rise time of NGF levels after cessation of anti-NGF block might not have been slowed significantly by persisting antibody action. A daily anti-NGF treatment was established specifically to hold collateral sprouting in check for approximately $25 \mathrm{~d}$, the period when unconditioned sprouting would be approaching its ceiling. This blocking dosage $(0.3 \mathrm{ml})$ turned out to be some $40 \%$ less than the standard dosage we routinely use to prevent collateral sprouting. The injections were begun on the day of field isolation and mapping, but were discontinued after $12 \mathrm{~d}$, when precocious sprouting would normally be well advanced. The time course of the subsequent sprouting is shown in Figure 8. Although only an approximate estimate, expansion of both the pinch and the heat fields appeared to be occurring at about $7 \mathrm{~d}$. (The control animals were first mapped on day 9 in this study, by which time the field expansions were clearly established.) Thus, in impulse-conditioned neurons, the latency of post-anti-NGF sprouting was similar to that of normal precocious sprouting. The rate and final extent of sprouting appeared to be somewhat lower than normal, however, in the anti-NGFtreated animals, an observation that needs further investigation. This observation indicates, however, that after anti-NGF treatment, the neurons were not more responsive to NGF than normal, a point of relevance to the Discussion below.

(2) Dose-response studies. This experiment was considered justified by the preceding results, which argued against a longlasting antibody action after anti-NGF injection. The experiment attempted to discover the shortest spacing between antiNGF injections that would just prevent the occurrence of sprouting. A lower-than-normal daily anti-NGF administration was selected $(0.2 \mathrm{ml}$ rather than $0.5 \mathrm{ml})$, even less than the reduced dosage used in the preceding experiment. From the results of that experiment, and numerous relatcd oncs, the sclected dosage was known to be barely adequate to maintain a sprouting block, and could therefore be confidently assumed to be not "saturating." This was indicated by the slight trend to-
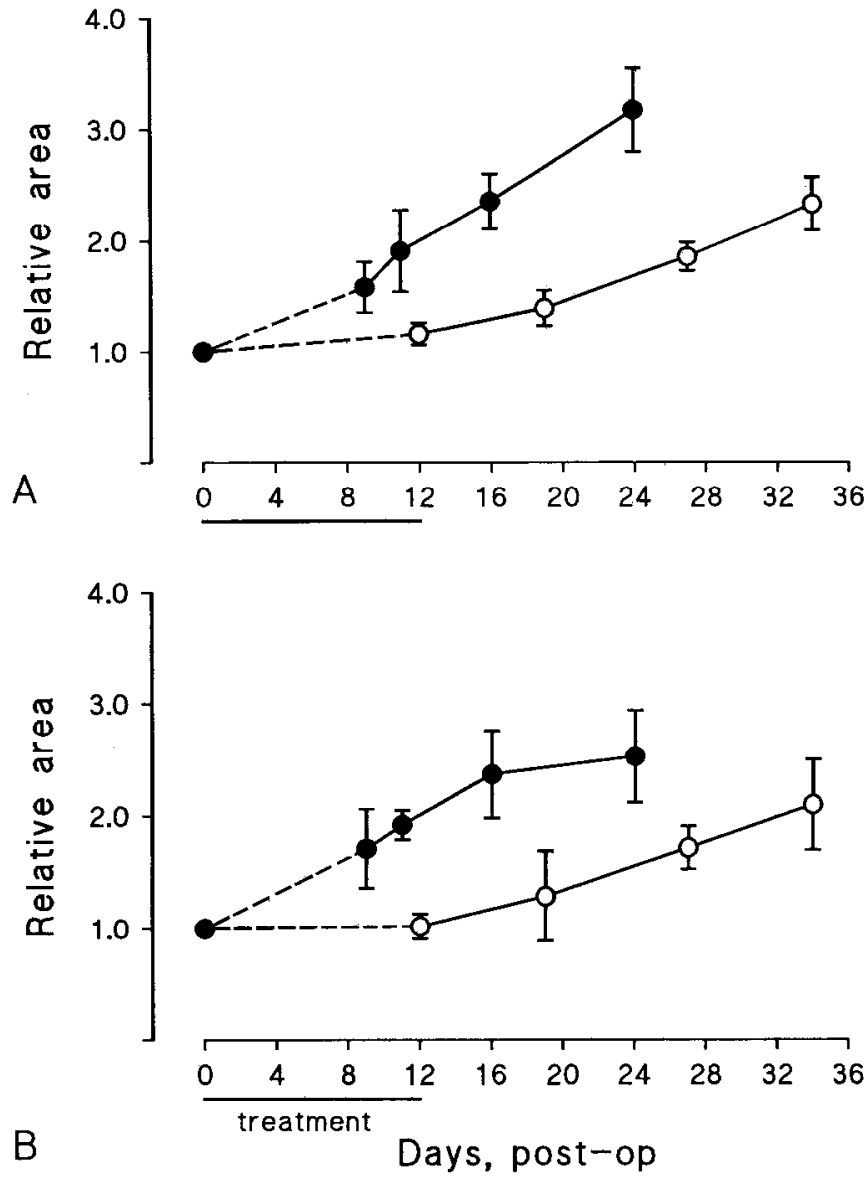

Figure 8. Latency of sprouting after cessation of anti-NGF block. $A$ and $B$ show precocious sprouting of pinch and heat nociceptive fibers, respectively, in animals that reccived $12 \mathrm{~d}$ of nonimmune serum injections (solid circles) or $12 \mathrm{~d}$ of anti-NGF injections (open circles), beginning on the day of field isolation. Error bars are \pm SEM. The latencies to the onset of the field expansions that followed the last anti-NGF injection are similar to the corresponding latencies of the usual precocious sprouting following field isolation (see Materials and Methods).

ward field expansion observed during daily injections, which just achieved statistical significance on the final time point (day 21 in Fig. 9). The interinjection interval was then progressively lengthened: in a second group of animals the injections were given on alternate days; in a third group, every third day; and in a fourth group, every fourth day.

The results show that the alternate day injections were hardly less effective than daily ones in preventing sprouting. With the $3 \mathrm{~d}$ injection intervals, however, significant sprouting occurred, although at a reduced rate. Injections every fourth day only slightly reduced the sprouting (as did a daily injection that was one-fourth of the dosage; not illustrated). The latency to the first detected sprouting, however, appeared to be approximately the same for all of the injection regimes, and in the normal range for precocious sprouting.

The suggested implications of the findings from these two studies are discussed below.

\section{Other effects of the anti-NGF treatment.}

In animals that had received anti-NGF treatment for 3-4 weeks, the Evans blue test, which was used to detect sensory $\mathrm{C}$-fibers, gave reduced responses; this finding is consistent with 


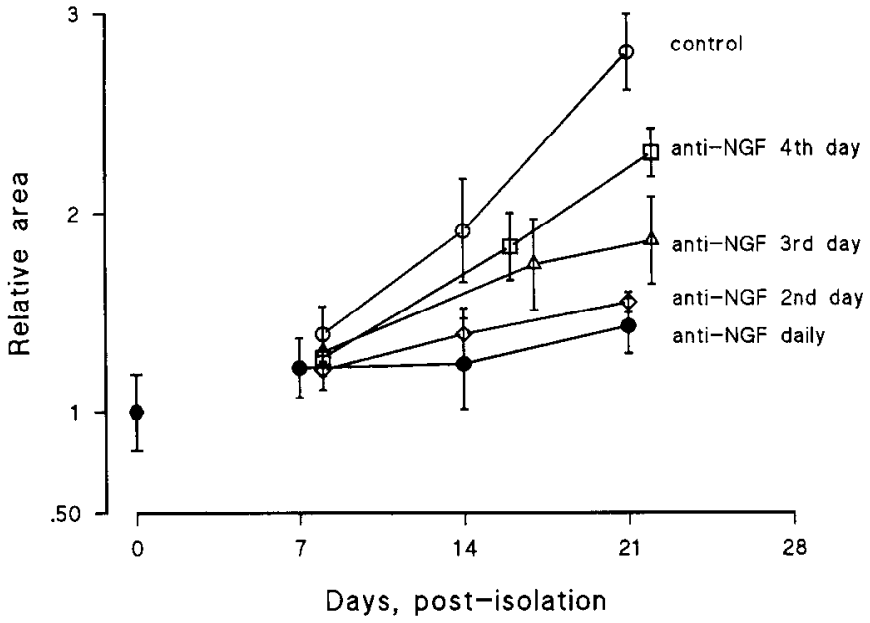

Figure 9. Anti-NGF dose-response study. The precocious sprouting paradigm was established in five groups of animals; in each group the field expansions were measured relative to the initial field value. The data shown are the mechanonociceptive findings, but those for the heatnociceptive fields were essentially similar. A control group received daily injections of nonimmune serum. Another group received daily antiNGF injections. The remaining three groups received anti-NGF injections, respectively, every second day, every third day, and every fourth day, as indicated. There was no significant difference in the findings at the three postisolation time intervals for the daily, and every-other-day, anti-NGF groups $(p>0.4)$; however, both groups showed a just significant expansion over the whole period of study $(p<0.04)$. The everythird-day injection group showed a significant expansion at days 7,17 , and $22(p<0.02)$.

a reduction having occurred in the SP content of these fibers (Lembeck and Holzer, 1979; Schwartz et al., 1982). We also compared the wet weights of SCG in anti-NGF-treated animals and in nonimmune serum-treated animals, all of comparable body weight. The results (Table 1) indicate that a significant shrinkage had indeed occurred following 25-28 d of anti-NGF treatment as compared with the controls (cf. Angeletti et al., 1971; Bjerre et al., 1975). Lesions have been reported often to develop in the neck region of anti-NGF-treated and autoimmunized animals (Gorin and Johnson, 1980). We, too, observed the development of atrophic, and apparently uninfected, lesions in the skin of the neck, and/or of the mystacial pad region, in about $90 \%$ of the animals that reccived our standard anti-NGF treatment for a minimum of 3-5 weeks. Atrophic lesions, however, also occurred in denervated areas of skin in $u n$ treated animals, almost certainly complicated by the tendency for selfmutilation in such animals. These lesions were more common, and faster developing, in anti-NGF-treated animals. There was never any evidence of distress in the animals, even when the lesions had enlarged to more than a few millimeters in diameter.

\section{Discussion}

\section{Collateral sprouting is $N G F$ dependent}

All the results relate to the collateral sprouting of intact nociceptive nerves into neighboring denervated skin of adult rats. Collateral sprouting would also be occurring within an isolated field that, because of the extensive overlapping of the fields of adjacent DCNs (Nixon et al., 1984; Doucette and Diamond, 1987), is itself partially denervated by the elimination of adjacent nerves (cf. Cooper et al., 1977). Unfortunately, our mapping technique does not permit an evaluation of changes in the density of nociceptive endings.

\begin{tabular}{|c|c|c|}
\hline & $\begin{array}{l}\text { Body weight } \\
(\mathrm{gm}, \pm \text { SEM) }\end{array}$ & $\begin{array}{l}\text { SCG weight } \\
(\mathrm{mg}, \pm \text { SEM })\end{array}$ \\
\hline Control animals & $130 \pm 4.4(n=8)$ & $148 \pm 0.08(n=16)$ \\
\hline Experimental animals & $143 \pm 4.7(n=7)$ & $0.95 \pm 0.07(n=14)$ \\
\hline
\end{tabular}

Control animals received daily injections of nonimmune serum for $33 \mathrm{~d}$; experimental animals received the routine dosage of anti-NGF serum for the same period.

The collateral sprouting that we measured appeared to be entirely dependent on endogenous NGF. It was prevented by antiserum to NGF but not by control serum, and the sprouting resumed when the anti-NGF treatment was terminated. AntiNGF treatment appeared effectively to halt collateral sprouting that had already begun, indicating that endogenous NGF is continually utilized by the growing neurites. Finally, intradermal injections of NGF itself (1) evoked collateral sprouting in normal fully innervated skin, (2) increased the rate of a sprouting that had already begun to invade adjacent denervated skin, and (3) substantially restored the rate of such sprouting when it had been held to a low level by an appropriate anti-NGF treatment. The last result, especially, helps confirm the assumption that the effect of anti-NGF administration in preventing collateral sprouting was due to the elimination or drastic reduction of endogenous NGF (or other growth factors recognized by the antiserum; see below) in the skin, and not through some other effect of the treatment (cf. Goedert et al., 1980). Although we needed relatively large doses of exogenous NGF to induce sprouting, this could well be related to the difficulty of achieving adequate concentrations in the vicinity of the sensory endings.

We must also consider the possibility that the endogenous growth factor involved is not NGF at all, but either brainderived neurotrophic factor (BDNF) or neurotrophin-3 (Hofer and Barde, 1988; Hohn et al., 1990; Hallböök et al., 1991); both of the latter neurotrophic agents are recognized by our polyclonal (sheep) anti-NGF, although BDNF recognition is relatively low (we are grateful to Dr. R. Murphy, University of Alberta, Edmonton, for providing us with this data). We shall continue to refer to NGF as the likely growth molecule throughout this report with the caveat implied by the above comment.

For most of their growth, the collateral sprouts in the present experiments appeared to be almost totally confined to the axondenuded perineurial tubes of the dermis, and the Schwann tubes of the horizontal subepidermal network. Thus, the source of the endogenous growth factor utilized for sprouting is likely to be associated with these pathways. A prime candidate has to be the Schwann cells themselves (Finn et al., 1986), which can certainly synthesize NGF in vitro (Assouline et al., 1987; Bandtlow et al., 1987; Heumann et al., 1987) and in vivo (Heumann et al., 1987; Brown et al., 1991). However, a number of other cell types in skin can synthesize NGF, including fibroblasts, keratinocytes, and smooth muscle cells (Rush, 1984; Murphy et al., 1986; Tron et al., 1990).

\section{Impulses and rate of NGF buildup determine the latency of collateral sprouting}

The usual time to the earliest detected onset of field expansion after its isolation was $10-12 \mathrm{~d}$. We estimate that at least $2 \mathrm{~d}$ of expansion must occur for it to be unambiguously identified by 
our mapping technique. Thus, normal collateral sprouting of nociceptive axons probably begins at most 8-10 d after surrounding denervation. This latency is reduced by 5-6 d ("precocious sprouting") if the fields are mapped at the time of their isolation. The reduction is attributable to the impulses evoked in the spared neurons by the examination procedure (Nixon et al., 1984; Doucette and Diamond, 1987); it can be produced by direct electrical stimulation of the nerve, and only the impulses conducted toward the cell body are effective (sprouting latency is unaffected by impulses reaching the nerve endings in the skin). The "corrected" latent period for the onset of precocious sprouting therefore can be as little as 2-3 d. This period includes (1) the time required for endogenous NGF to build up to effective levels in the denervated skin, and (2) the time taken by the neuronal mechanisms associated with the initiation of sprouting to become effective. It is the latter "initiation time" that is so dramatically affected by impulse activity. We tried to estimate this component of the sprouting latency indirectly, by addressing the NGF buildup time (the experiments described in section 5 of the Results).

Among the unknowns that complicate those experiments are the levels of NGF in normally innervated skin. We have not yet measured these levels, but they are likely to be low (cf. Tron et al., 1990). Our preliminary results (K. Mearow, Y. Kril, G. Ross, and J.' Diamond, unpublished observations) do show that NGF mRNA expression is low in normal rat skin, but interestingly [and in contrast to in vivo findings from iris (Shelton and Reichardt, 1986b) and hippocampus (Korsching et al., 1986)], this expression increases significantly in denervated skin. The most important unknown, however, is the duration of antiNGF effectiveness after its injection. A relevant finding was that the precocious sprouting latency following cessation of an antiNGF block was similar to that following initial field isolation. Thus, the time for endogenous NGF to rise to threshold levels was probably similar in the two situations. Our results certainly appeared to eliminate the possibility that, following antibody administration, sprouting would have been initiated sooner than usual in response to an increasing level of endogenous NGF. Possibly, in the two experiments being compared, the rise time of NGF in denervated skin was slowed equally, on the one hand by residual NGF uptake into axotomized terminals, and on the other by persisting effectiveness of anti-NGF antibodies after the final injection. In the absence of information on the former, we opt for the simplest interpretation of the findings, namely, that the duration of antibody effectiveness was relatively limited (to less than $1 \mathrm{~d}$, certainly).

The results of the dose-response studies can be explained very simply on the basis of this interpretation. While sprouting was blocked by a nonsaturating anti-NGF dose administered every day or every second day, a significant sprouting occurred if an extra (third) day went by without an injection. We propose, therefore, that a little over $2 \mathrm{~d}$ was required for the NGF levels to increase from the assumed low value after each injection, to the minimum needed for collateral sprouting to occur. It follows, then, that a similar time is required for endogenous NGF concentrations to rise to threshold values following denervation of skin. Given that the latency of precocious sprouting can be as low as $2-3 \mathrm{~d}$, as explained above, the neuronal "initiation time" must occupy only about $1 \mathrm{~d}$, and could be less than this. The latency of the precocious sprouting seemed to be relatively independent of the spacing of the anti-NGF injections. Its most significant feature, however, was its extraordinary sensitivity to impulse activity. Interestingly, the latency of precocious sprouting is similar to that reported for the collateral sprouting of spared axons in other systems, such as skeletal muscle (Brown and Ironton, 1978) and the hippocampus (Cotman and Anderson, 1988). Conceivably, the ongoing impulse activity in motor nerves, and in septohippocampal fibers, might be affecting the sprouting latency in a manner analogous to that for sensory nerves. A similar explanation (in this instance involving impulses generated by the testing protocol) could explain the unusually rapid sprouting reported for nociceptive nerves in the rat paw by Devor et al. (1979), as discussed in Nixon et al. (1984).

\section{The possible mode of action of impulses in reducing sprouting} latency

The rate of sprouting was unaffected by impulses and seemed to be wholly determined by the level of endogenous NGF. Thus, some component of the impulse-sensitive neuronal mechanisms that initiate the sprouting response seems not to be shared by the mechanisms that underlie the observed collateral sprouting. Nevertheless, the action of impulses in accelerating the onset of sprouting was itself abolished by a brief coincident anti-NGF treatment (the subsequent sprouting then appearing with its normal latency). This need for at least some endogenous NGF to be available for impulses to exert their priming action recalls the NGF priming described for PC12 cells (Greene et al., 1982); although impulses did not appear to be involved, the neurite production by these cells in response to NGF was accelerated if there had been a prior exposure of the cells to the samc growth molecule. A newly described protein, neurogranin/BICKS (Represa et al., 1990; Coggins et al., 1991), that shares immunoreactivity and has partial homology with GAP43/B-50 has recently been shown to have a similar effect, apparently sensitizing $\mathrm{PC} 12$ cells to the subsequent neurite-promoting action of NGF (P. J. Coggins, J. Stanisz, and J. Diamond, unpublished observations). In all of these situations, involving both sensory neurons and PC12 cells, the time required for the "unconditioned" (naive) cells to begin neurite production was a number of days, and after priming this time was reduced to a matter of hours. Conceivably, these priming influences (impulses, NGF, and possibly neurogranin/BICKS) exert their effects at a common locus in the chain of events leading to neuritic outgrowth.

To bring about precocious sprouting, the conditioning impulses have to be conducted toward the cell bodies (Nixon et al., 1984; Doucette and Diamond, 1987). We suggest that the action of these impulses, which is exerted only in the presence of endogenous NGF, is to prime, or sensitize, the cellular mechanisms that initiate the sprouting response. A number of transcriptional events are known to be sensitive to impulse activity in neurons, and of particular interest is the transient expression of DNA-binding proteins, some of which have been identified as an early response of neurons to transsynaptic excilation, neuromodulators, and growth factors (Sheng and Greenberg, 1990). Of special relevance may be the rapid rise in c-fos expression, which precedes the increased expression of NGF receptor in dorsal root ganglia (DRG) neurons in vitro in response to NGF (Lindsay et al., 1990). Although c-fos was found not to be induced in DRG neurons by impulse activity (Hunt et al., 1987), an upregulation of c-jun has been observed following sciatic nerve crush (Jenkins and Hunt, 1991). Recently it was reported that the induction of c-fos in cultured sympathetic ncurons by trauma occurred only in the presence of NGF (Buckmaster et 
al., 1991). Thus, the regulation of gene expression by products of immediate early-response genes could well be involved in both normal and precocious collateral sprouting.

We are especially interested in the possibility that impulses may cause a rapid increase in the rate of NGF utilization by an upregulation of NGF receptor (NGF-R) expression and/or an increased rate of its internalization, especially given (1) the relatively rapid rise of endogenous NGF levels after denervation (from very low to threshold in 2 d), (2) that NGF itself can upregulate the expression of NGF-R (Lindsay et al., 1990; Miller ct al., 1991), and (3) that a minimum level of endogenous NGF is necessary for conditioning impulses to be effective at all. Our preliminary results in this context show that NGF-R mRNA expression is increased in DRG neurons undergoing collateral sprouting (Mearow et al., 1991), in contrast to NGF-R downregulation (measured as reduced NGF binding) during axonal regeneration (Verge et al., 1989).

\section{The significance of precocious sprouting}

Plasticity in the nervous system. We have no direct evidence that precocious sprouting occurs elsewhere in the nervous system, although we have preliminary indications of this possibility for the collateral sprouting of septohippocampal fibers in the hippocampus (C. E. E. M. Van der Zee, R. Racine, and J. Diamond, unpublished observations). The concept of a co-involvement of impulses and endogenous growth factors in the regulation of sprouting is particularly appealing as one basis of neuronal plasticity in the adult nervous system. Such an interaction might contribute to long-term changes, for example, those involved in learning, in which impulse activity is a key feature. In this context, it is interesting that in the present study exogenous NGF could evoke a functional sprouting of nociceptive nerves within normally innervated skin. Thus, the normal density of nociceptive terminals might well be limited by the availability of endogenous NGF. An ongoing competition between nerves for NGF (cf. Korsching and Thoenen, 1985) would clearly be influenced by the relative abilities of competing neurons to make and deliver NGF receptors to their terminals. If impulse activity were able to influence NGF-R expression, it would be able to influence the relative densities of axonal terminals within a shared target tissue.

The embryological origin of the sensory neurons that undergo $N G F$-dependent sprouting in the adult. The NGF dependency of sensory nerve sprouting seems likely to be related to the NGF dependency of the same neurons during development. The unmyelinated heat-nociceptive nerves are assumed to derive from the "small dark" cells in the DRG (Lieberman, 1976), whose survival is critically dependent on NGF before and for a short period after birth (Johnson et al., 1980; Ross et al., 1981; Goedert et al., 1984; Yip et al., 1984). At least some of the mechanonociceptive A $\delta$-fibers could derive from the "large pale" cells (presumably the smallest of these; see Lawson et al., 1985), but it is not clear whether the latter neurons are also NGF dependent during development (Hamburger et al., 1981; Straznicky and Rush, 1985; Keller et al., 1990). From the present findings, both nociceptive fiber classes certainly share a common NGF-related growth characteristic in the adult animal. In mammals, lowthreshold mechanosensory nerve sprouting has been observed only in the dorsal skin of very young rat pups (Jackson and Diamond, 1984), although not in their glabrous skin (Mills et al., 1989). We have not yet determined whether NGF is also involved in this temporally and regionally limited $\mathrm{A} \alpha$-fiber sprouting in the rat pup, or that of the analogous mechanosensory axons associated with the Merkel cells in the (glabrous) skin of adult salamander (Cooper et al., 1977). Recent in vitro studies suggest that during development mammalian Merkel cells are likely sources of NGF for their innervating nerves (Vos et al., 1991), although Merkel cells are not associated with the major population of low-threshold mechanosensory axons that supply the hairs in non-glabrous skin. If NGF is indeed responsible for the sprouting of at least a subpopulation of A $\alpha$ axons during development, then their failure to undergo collateral sprouting in the mature animal (Jackson and Diamond, 1984) might be due to their becoming NGF unresponsive. These low-threshold axons are unaffected by either the administration of exogenous NGF, or the rise in local endogenous NGF levels consequent to adjacent denervation, both of which evoke the vigorous sprouting of nociceptive axons in their immediate vicinity.

Therapeutic considerations. Precocious sprouting could make a critical contribution to the recovery of nociceptive function after traumatic injuries that result in partial denervation of skin, since spared nociceptive fibers would almost certainly have been coincidentally activated. An impulse-accelerated sprouting would also facilitate the provision of trophic support for neighboring denervated skin, helping to preserve its viability, possibly until the sprouts were displaced consequent to the regeneration of its former axons (Diamond et al., 1976; Devor et al., 1979). If precocious sprouting proved to be a more widespread feature within the nervous system, similar considerations to those discussed in this report might apply to the presumed beneficial effects of activity or exercise on the recovery of function following lesions of the CNS (e.g., Black et al., 1975).

\section{References}

Aguayo A, David S, Richardson P, Bray G (1982) Axonal elongation in peripheral and central nervous system transplants. Adv Cell Biol $3: 215-234$

Aloe LP, Cozzari R, Calissano R, Levi-Montalcini R (1981) Somatic and behavioral postnatal effects of fetal injections of nerve growth factor antibodies in rats. Nature 291:413-415.

Angeletti PU, Levi-Montalcini R, Caramia F (1971) Analysis of the effects of the antiserum to the nerve growth factor in adult mice. Brain Res 27:343-355.

Assouline JG, Bosch P, Lin R, Kim IS, Jensen R, Pantazis NJ (1987) Rat astrocytes and Schwann cells in culture synthesize nerve growth factor-like neurite-promoting factor. Dev Brain Res 31:103-118.

Bandtlow CE, Heumann R, Schwab ME, Thoenen H (1987) Cellular localization of nerve growth factor synthesis by in situ hybridization. EMBO J 6:891-899.

Bjerre B, Wiklund L, Edwards DC (1975) A study of the de- and regenerative changes in the sympathetic nervous system of the adult mouse after treatment with antiserum to nerve growth factor. Brain Res 92:257-278.

Black P, Markowitz RS, Cianci SN (1975) Recovery of motor functions after lesion in motor cortex of monkey. In: Ciba Foundation symposium 34 , Outcome of severe damage to the central nervous system (Fitzsimmons DW, ed), pp 65-70. Amsterdam: Elsevier.

Brown MC, Ironton R (1978) Sprouting and regression of neuromuscular synapses in partially denervated mammalian muscle. J Physiol (Lond) 278:325-348.

Brown MC, Perry VH, Lun ER, Gordon S, Heumann R (1991) Macrophage dependence of peripheral sensory nerve regeneration: possible involvement of nerve growth factor. Neuron 6:359-370.

Buckmaster A, Nobes CD, Edwards SN, Tolkovsky AM (1991) NGF is required for induction of $\mathrm{c}$-fos immunoreactivity by serum, depolarization, cyclic AMP or trauma in cultured rat sympathetic neurons. Eur J Neurosci 3:697-707.

Burnette WN (1981) Western blotting: electrophoretic transfer of proteins from sodium dodecyl sulfate-polyacrylamide gels to unmodified 
nitrocellulose and radiographic detection with antibody and protein A. Anal Biochem 142:195-203.

Cauna N (1969) The fine morphology of the sensory receptor organs in the auricle of the rat. J Comp Neurol 136:81-98.

Coggins P, Stanisz J, Nagy A, Zwiers H (1991) Identification of a calmodulin-binding, B-50-immunoreactive C-kinase substrate (BICKS) in bovine brain. Neurosci Res Commun 8:49-53.

Cooper E, Diamond J, Turner C (1977) The effects of nerve section and of colchicine treatment on the density of mechanosensory nerve endings in salamander skin. J Physiol (Lond) 264:725-749.

Cotman CW, Anderson KJ (1988) Synaptic plasticity and functional stabilization in the hippocampal formation: possible role in Alzheimer's disease. Adv Neurol 47:313-335.

Coughlin MD, Collins MB (1985) Nerve growth factor-independent development of embryonic mouse sympathetic neurons in dissociated cell culturc. Dev Biol 110:392-401.

Darling TL, Shooter EM (1984) Preparation and assay of nerve growth factor. In: Methods for serum-free culture of neuronal and lymphoid cells (Barnes DW, Sirbasku DA, Sato GH, eds), pp 79-93. New York: Liss.

Davies AM, Bandtlow C, Heumann R, Korsching S, Rohrer H, Thoenen $H$ (1987) Timing and site of nerve growth factor synthesis in developing skin in relation to innervation and expression of the receptor. Nature 326:353-358.

Devor M, Schonfield D, Seltzer Z, Wall PD (1979) Two modes of cutaneous reinnervation following peripheral nerve damage. J Comp Neurol 185:211-220.

Diamond J, Cooper E, Turner C, Macintyre L (1976) Trophic regulation of nerve sprouting. Science 193:371-377.

Diamond J, Coughlin M, Macintyre L, Holmes M, Visheau B (1987) Evidence that endogenous NGF is responsible for the collateral sprouting, but not the regeneration, of nociceptive axons in adult rats. Proc Natl Acad Sci USA 84:6596-6600.

Diamond J, Holmes M, Visheau B (1988) NGF-regulated plasticity in the adult nervous system. Soc Neurosci Abstr 14:245.6.

Diamond J, Foerster A, Holmes M, Coughlin M (1992) Sensory nerves in adult rats regenerate and restore sensory function to the skin independently of endogenous NGF. J Neurosci 12:1467-1476.

Doucette R, Diamond J (1987) The normal and precocious sprouting of heat nociceptors in the skin of adult rats. J Comp Neurol 261:592603.

Finn PJ, Ferguson IA, Renton FJ, Rush RA (1986) Nerve growth factor immunohistochemistry and biological activity in the rat iris. J Neurocytol 15:169-176.

Gage FH, Armstrong DM, Williams LR, Varon S (1988) Morphological response of axotomized septal neurons to nerve growth factor. J Comp Neurol 269:147-153.

Goedert M, Otten U, Shäfer T, Schwab M, Thoenen H (1980) Immunosympathectomy: lack of evidence for a complement-mediated cytotoxic mechanism. Brain Res 201:399-409.

Goedert M, Otten U, Hunt SP, Bond A, Chapman D, Schlumpf M, Lichtensteiger W (1984) Biochemical and anatomical effects of antibodies against nerve growth factor on developing rat sensory ganglia. Proc Natl Acad Sci USA 81:1580-1584.

Gorin PD, Johnson EM (1979) Experimental autoimmune model of nerve growth factor deprivation: effects on developing peripheral sympathetic and sensory neurons. Proc Natl Acad Sci USA 76:53825386.

Gorin PD, Johnson EM (1980) Effects of long term nerve growth factor deprivation on the nervous system of the adult rat: an experimental autoimmune approach. Brain Res 198:27-42.

Greene LA (1977) A quantitative bioassay for nerve growth factor (NGF) activity employing a clonal phaeochromocytoma cell line. Brain Res 133:350-353.

Greene LA, Burstein DE, Black MM (1982) The role of transcriptiondependent priming in nerve growth factor promoted neurite outgrowth. Dev Biol 91:305-316.

Greenwood FC, Hunter WM, Glover JS (1963) The preparation of $I^{131}$, labelled human growth hormone of high specific radioactivity. Biochem J 89:114-123.

Hagg T, Manthorpe M, Vahlsing HL, Varon S (1988) Delayed treatment with nerve growth factor reverses the apparent loss of cholinergic neurons after acute brain damage. Exp Neurol 101:303-312.

Hallböök F, Ibánez C, Persson H (1991) Evolutionary studies of the nerve growth factor family reveal a novel member abundantly expressed in Xenopus ovary. Neuron 6:845-858.
Hamburger V, Brunso-Bechtold JK, Yip JW (1981) Neuronal death in the spinal ganglia of the chick cmbryo and its reduction by nerve growth factor. J Neurosci 1:60-71.

Heumann R, Korsching S, Scott J, Thoenen H (1984) Relationship between levels of nerve growth factor (NGF) and its messenger RNA in sympathetic ganglia and peripheral target tissues. EMBO J 3:31833189.

Heumann R, Lindholm D, Bandtlow C, Meyer M, Radeke MJ, Misko TP, Shooter E, Thoenen H (1987) Differential regulation of mRNA encoding nerve growth factor and its receptor in rat sciatic nerve during development, degeneration, and regeneration: role of macrophages. Proc Natl Acad Sci USA 84:8735-8739.

Hofer MM, Barde YA (1988) Brain-derived neurotrophic factor prevents neuronal death in vivo. Nature 331:261-262.

Hohn A, Leibrock J, Bailey K, Barde YA (1990) Identification and characterization of a novel member of the nerve growth factor/brainderived neurotrophic factor family. Nature 344:339-341.

Hunt P, Pini A, Evan G (1987) Induction of c-fos-like protein in spinal cord neurons following sensory stimulation. Nature 328:632-634.

Jackson P, Diamond J (1984) Temporal and spatial constraints on the collateral sprouting of low-threshold mechanosensory nerves in the skin of rats. J Comp Neurol 226:336-345.

Jenkins R, Hunt SP (1991) Long-term increase in the level of c-jun mRNA and jun protein-like immunoreactivity in motor sensory neurons following axon damage. Neurosci Lett 129:107-110.

Johnson EM, Gorin PD, Brandeis LD, Pearson J (1980) Dorsal root ganglion neurons are destroyed by exposure in utero to maternal antibodies to nerve growth factor. Science 210:916-918.

Kenins $P$ (1981) Identification of the unmyelinated sensory nerves which evoke plasma extravasation in response to antidromic stimulation. Neurosci Lett 25:137-141.

Keller A, Williams R, Vahaviolos J, Auffray C, Rush RA (1990) Immunohistochemical localization of nerve growth factor in a subpopulation of chick spinal ganglion neurons. J Neurosci Res 27:136143.

Korsching S, Thoenen $\mathrm{H}$ (1985) Nerve growth factor supply for sensory neurons: site of origin and competition with the sympathetic nervous system. Neurosci Lett 54:201-205.

Korsching S, Heumann R, Thoenen H, Hefti F (1986) Cholinergic denervation of the rat hippocampus by fimbrial transection leads to transient accumulation of nerve growth factor (NGF) without change in mRNA NGF content. Neurosci Lett 66:175-179.

Kruger L, Perl ER, Sedivec MJ (1981) Fine structure of myelinated mechanical nociceptive endings in cat hairy skin. J Comp Neurol 198 : 137-154.

Lawson SN, Harper EL, Garson JA, Coakham HB, Randles BJ (1985) Monoclonal antibody 2C5: a marker for a subpopulation of small neurons in rat dorsal root ganglia. Neuroscience 16:365-374.

Lembeck F, Holzer P (1979) Substance P as a neurogenic mediator of antidromic vasodilation and neurogenic plasma extravasation. Naunyn Schmiedebergs Arch Pharmacol 310:175-183.

Levi-Montalcini R, Angeletti PI (1968) Nerve growth factor. Physiol Rev 48:534-569.

Lieberman AR (1976) Sensory ganglia. In: The peripheral nerve (Landon DN, ed), pp 188-278. New York: Chapman and Hall.

Lindsay RM, Shooter EM, Radeke MJ, Misko TP, Dechant G, Thoenen $H$, Lindholm D (1990) Nerve growth factor regulates expression of the nerve growth factor receptor gene in adult sensory neurons. Eur J Neurosci 2:389-396.

Loots GP, Loots JM, Brown JM, Schoeman J (1979) A rapid silver impregnation method for nervous tissue. Stain Technol 54:97-100.

Mearow K, Ross G, Kril Y, Gloster A, Holmes M, Diamond J (1991) Changes in NGF receptor and GAP43 mRNA associated with collateral sprouting and regeneration of dorsal cutaneous nerves in the rat. Soc Neurosci Abstr 17:1312.

Millard CL, Woolf CJ (1988) Sensory innervation of the hairs of the rat hind limb: a light microscopic analysis. J Comp Neurol 277:183194.

Miller FD, Coughlin MD, Jang DE, Stanisz J, Sauder DN (1991) Regulation of nerve growth factor receptor gene expression by nerve growth factor in the developing peripheral nervous system. J Cell Biol 112:303-312.

Mills LR, Nurse CA, Diamond J (1989) The neural dependency of Merkel cell development in the rat: the touchdomes and foot pads contrasted. Dev Biol 136:61-74.

Mobley WC, Schenker A, Shooter EM (1976) Characterization and 
isolation of proteolytically modified nerve growth factor. Biochemistry 15:5543-5551.

Mobley WC, Rutkowski JL, Tennekoon GI, Buchanan K, Johnston MV (1985) Choline acetyltransferase activity in striatum of neonatal rats increased by nerve growth factor. Science 225:284-287.

Murphy RA, Landis SC, Bernanke J, Siminoski K (1986) Absence of the $\alpha$ and $\gamma$ subunits of 75 nerve growth factor in denervated rodent iris: immunochemical studies. Dev Biol 114:369-380.

Nixon BJ, Doucette R, Jackson P, Diamond J (1984) Impulse activity evokes precocious sprouting of nociceptive nerves into denervated skin. Somatosensory Res 2:97-126.

Represa A, Delouline JC, Sensenbrenner M, Ben-Ari Y, Bandier J (1990) Neurogranin: immunocytochemical localization of brain-specific protein kinase C substrate. J Neurosci 10:3782-3792.

Reynolds ES (1963) The use of lead citrate at high $\mathrm{pH}$ as an electronopaque stain in electron microscopy. J Cell Biol 17:202-212.

Ross M, Lofstrandh S, Gorin PG, Johnson EM, Schwartz JP (1981) Use of an experimental autoimmune model to define nerve growth factor dependency of peripheral and central substance $P$ containing neurons in the rat. J Neurosci 1:1304-1311.

Rush RA (1984) Immunohistochemical localization of endogenous nerve growth factor. Nature 312:364-376.

Schwartz JP, Pearson J, Johnson EM (1982) Effects of exposure to anti-NGF on sensory neurons of adult rats and guinea pigs. Brain Res 244:378-381.

Shelton D, Reichardt LF (1984) Expression of the $\beta$-nerve growth factor gene correlates with the density of sympathetic innervation in effector organs. Proc Natl Acad Sci USA 81:7951-7955.

Shelton DL, Reichardt LF (1986a) Studies on the expression of the $\beta$ nerve growth factor (NGF) gene in the central nervous system. Level and regional distribution of NGF $m$ RNA suggests that NGF functions as a trophic factor for several distinct populations of neurons. Proc Natl Acad Sci USA 83:2714-2718.

Shelton DL, Reichardt LF (1986b) Studies on $\beta$-nerve growth factor gene expression in the rat iris: the level of mRNA-encoding nerve growth factor is increased in irises placed in explant cultures in vitro, but not in irises deprived of sensory or sympathetic innervation in vivo. I Cell Biol 102:1940-1948.

Sheng M, Greenberg ME (1990) The regulation and function of $c$-fos and other immediate early genes in the nervous system. Neuron 4: $77-85$.

Simpson SA, Young JZ (1945) Regeneration of fiber diameter after cross unions of visceral and somatic nerves. J Anat 79:48-65.

Spurr AR (1969) A low-viscosity epoxy resin embedding medium for electron microscopy. J Ultrastruct Res 26:31-43.

Stach RW, Wagner BJ, Stach BM (1977) A more rapid method for the isolation of the $7 \mathrm{~S}$ nerve growth factor complex. Anal Biochem 83:26-32.

Straznicky C, Rush RA (1985) Nerve growth factor treatment does not prevent dorsal root ganglion cell death induced by target removal in chick embryo. Anat Embryol (Berl) 171:357-363.

Theriault E, Diamond J (1988) Nociceptive cutaneous stimuli evoke localized contractions in a skeletal muscle. J Neurophysiol 60:446462.

Towbin H, Staehlin T, Gordon J (1979) Electrophoretic transfer of proteins from polyacrylamide gels to nitrocellulose sheets: procedures and some application. Proc Natl Acad Sci USA 76:4350-4354.

Tron VA, Coughlin MD, Jang DE, Stanisz J, Sauder DN (1990) Expression and modulation of nerve growth factor in murine keratinocytes (PAM212). J Clin Invest 85:1085-1089.

Varon S, Nomura J, Shooter EM (1967) Isolation of mouse nerve growth factor in high molecular weight form. Biochemistry 6:22022209 .

Verge VMK, Riopelle RJ, Richardson PM (1989) Nerve growth factor receptors on normal and injured sensory neurons. J Neurosci 9:914 922.

Vos P, Stark F, Pittman RN (1991) Merkel cells in vitro: production of nerve growth factor and selective interactions with sensory neurons. Dev Biol 144:281-300.

Whittemore SR, Ebendal TE, Larkfors L, Olsen L, Seiger A, Stromberg I, Persson H (1986) Developmental regional expression of $\beta$ nerve growth factor messenger RNA and protein in the rat central nervous system. Proc Natl Acad Sci USA 83:817-821.

Yip HK, Rich KM, Lampe PA, Johnson EM (1984) The effects of nerve growth factor and its antiserum on the postnatal development and survival after injury of sensory neurons in rat dorsal ganglia. $J$ Neurosci 4:2986-2992. 